\title{
An Adaptive and Decentralized Protection Scheme for Microgrid Protection
}

\author{
Mahdi Ghotbi Maleki ${ }^{1 *}$, Hamid Javadi ${ }^{1 * *}$, Mojtaba Khederzadeh ${ }^{1 * * *}$, and Siamak Farajzadeh ${ }^{2}$ \\ ${ }^{1}$ Departmant of Electrical and Computer Engineering, Shahid Beheshti University, Tehran, Iran \\ ${ }^{2}$ Tehran Jonub Branch, Islamic Azad University, Tehran, Iran \\ *m_ghotbi@sbu.ac.ir, **javadi@pwut.ac.ir,***m_khederzadeh@sbu.ac.ir
}

\begin{abstract}
In this paper a protection scheme is provided to protect microgrid by considering the problems that are generated by addition of distributed generators to distribution networks and change these networks from passive to active. At first, changes in microgrid conditions that can affect short-circuit current is explained. Then Based on these changes, an algorithm is proposed to update relays settings. The algorithm can be used for both instantaneous and inverse time relays. In this protection scheme, central unit has no place and relays are responsible for monitoring microgrid and update their settings. In other words, this protection scheme is an adaptive and decentralized microgrid protection scheme.
\end{abstract}

Instantaneous overcurrent relays are used in this paper. To avoid storing large amounts of setting data in relays memory, a method for calculating pickup current of instantaneous relay is provided. Since digital relays used, a new characteristic curve for instantaneous relay for better performance in the field of backup protection is defined. This new characteristic curve has two peakup currents: one of them for main protection and the other one for backup protection. Then coordination of instantaneous relay using the new characteristic curve is explained. At the end, this protection scheme is implemented on a microgrid.

Keyword: adaptive protection, decentralized protection, microgrid protection, backup protection, instantaneous relays characteristic curve, instantaneous relays coordination, DG, GOOSE message, IEC 61850

\section{INTRODUCTION}

There are numerous advantages in the use of DG that increase the penetration level of these sources in power system, particularly in the distributed networks. For right management of DGs, microgrid concept has emerged. Microgrid composed of DGs and loads, and it is able to connect to external grid or separate from it. When a microgrid is used, DG do not have to respond to all changes in external grid. For example, if a fault occurs in external grid, microgrid quickly separates from external grid and DGs do not injected any current to this short-circuit. Therefore, microgrid protection schemes must be distinct and separate from external grid protection [1].

The fundamental problem in microgrid protection is its dynamic structure. Microgrid due to factors such as frequent entry and exit of DG, connection to external grid or independence of it, has a dynamic structure [2]. Relay used in microgrid should be able to properly carry out its protective duties. In other words, dynamic structure of microgrid should

2016 Power System Protection and Control Conference (PSPC), Tehran, Iran not affect the performance of the relay. Various methods have been proposed in other papers to protect microgrid. Some of these projects are based on conventional schemes and try to develop these conventional designs to be used in a new environment called microgrid. Some papers also try to define new schemes or equipment to protect the microgrid.

One of the microgrid protection schemes is adaptive protection. Adaptive protection is an online protection scheme that detects change in microgrid conditions and changes relays settings based on these changes. Adaptive protection schemes are based on conventional overcurrent protection. In this protection scheme, in most cases digital relays and telecommunications links are used to connect and transfer data between components. Following this section investigation of a few of these protection schemes will be discussed. In most of these projects, central system will be used to monitor the microgrid and do calculations. Central system data is transmitted to relays via telecommunication links. In some of the schemes central system clears faults itself and the relay is not used.

In [3] the central system with every change in the structure of microgrid, predicts characteristic curve of each relay and by using the telecommunication sends data to the relays. Relays do their Protective tasks using the new curve. The authors in [4-6] have suggested a protective scheme that by using of telecommunications, monitors microgrid and updates instantaneous overcurrent relays. In this protection scheme, centralized protection unit is defined that is associated with relays and DGs, and by change in DGs status, it changes relays settings. Ref. [7] uses local controller for recognizing small changes such as entry and exit of DGs and for recognizing big changes like microgrid separation from external grid, central system and telecommunications are used. Ref. [8] uses the central system and telecommunications to update the instantaneous relays settings. In [9] optimization methods for coordination of directional overcurrent relays are used. The proposed algorithm has two parts, the first part calculates $\mathrm{I}_{\text {set }}$ by $\mathrm{PSO}^{2}$ algorithm and the second part is for computing TMS of each relay by $\mathrm{LP}^{3}$ method. Calculations have been done offline in central unit, and with any change in microgrid conditions, settings will be sent to relays in an online way. In [10], expert systems for coordinating reverse time relays are used.

In [11] Each DG models with a voltage source series with a Thevenin impedance. Central system by monitoring the microgrid and calculating the Thevenin impedance can detect the occurrence of short-circuit and clear it. In [12] Central unit is defined to protect and control microgrid. This central unit 
by using telecommunication, receives data from equipment on each bas and issues control and protection decisions.

In [13] different scenarios of microgrid studied and overcurrent relays settings for these scenarios are calculated and stored in the relays memory. Relays themselves recognize changes in microgrid conditions by telecommunications and change their settings. In [14] central system and telecommunicated are not used and relays by measuring the seen impedance try to match their settings with the microgrid condition. In [15] a protection scheme is described that there is no need to create communication link and to be aware of other information over the network to detect changes in the microgrid. Considering different times for switches reclosing, relays will have the ability to detect fault location and by determining which generator is lost, relays will able to update their settings based on the amounts stored in their memories.

In the case of using telecommunications, microgrid changes monitoring will be done in a best way and with minimal error. But if the connection of central system is interrupted, the entire protection scheme fails. Because of the advantages and disadvantages of telecommunications, in this article, the author tried to mostly utilize advantages of the telecommunications and cover its defects. In this regard, the central system tasks assigned to the relays. That is, instead of the central system, relays are responsible to monitor microgrid and change their settings. That way, if one of the relays with a task similar to the central system lost its telecommunications connection, the upstream relay can support the specific relay and clear the short-circuit after a certain time.

IEC 61850 standard [16] is one of the defined standards in the field of smart grid. At first this standard aims to create substation automation but over time its goal was improved to create automation in whole power system. In [17] that was written by the authors of this paper, is explained how data exchange between different equipment of microgrid are provided in this protection scheme. This is possible when the equipment used in this protection scheme support IEC 61850 standard. The definition of data exchange based on IEC 61850 suggests this protection scheme does not need unconventional data so possibility of implement this protection scheme will increase in the real world.

This paper consists of 5 sections. In section 2 an adaptive and decentralized protection scheme for microgrid protection is presented. In this protection scheme, relays using telecommunications, monitor microgrid conditions and by detecting new changes in the microgrid conditions, update their settings. This protection scheme can be used for different types of inverse and instantaneous overcurrent relays as well.
Then updating of relay settings has been done based on this proposed scheme. By defining a new characteristic for the instantaneous digital relay in the next step of this paper, the author will discuss how instantaneous relay is coordinated with new character and presents backup protection design based on this new character. In section 3 values are calculated for use in the proposed protection scheme. Section 4 deals with the implementation of the proposed scheme on a microgrid. Section 5 is the conclusion.

\section{SUGGESTED PROTECTION SCHEME}

Most of the distributed networks contain DG which could be considered as a microgrid, possess potent meshed structure but they are deployed as a radial structure. Meshed structure enjoys advantages such as capability of feed loads through different routes and continuity in electrification. For instance in Fig. 1, if Line5 gets out of service for any reason, load and DG of Bas5 still could be connected to the microgrid using Line4. Different structures of microgrid represented in Fig. 2. With any change in structure of microgrid, equivalent impedance observed by sources will be changed. Therefore short-circuit current level will be changed consequently. To have efficient protection performance, the microgrid must be monitored and updated relays setting according a sudden change in microgrid conditions. Additional to change in microgrid structure, connection of microgrid to the external grid or disconnecting from it and DGs connection or disconnection could affect the short-circuit current level.

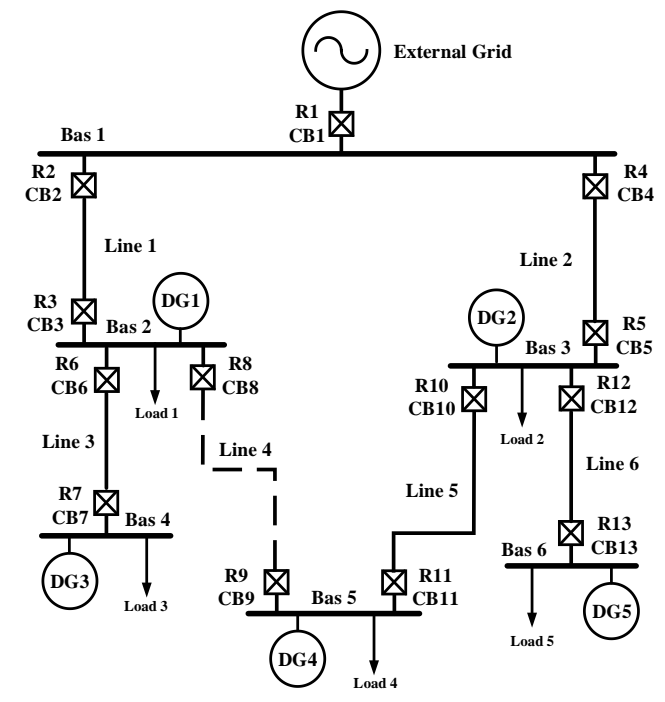

Figure 1. Studied microgrid

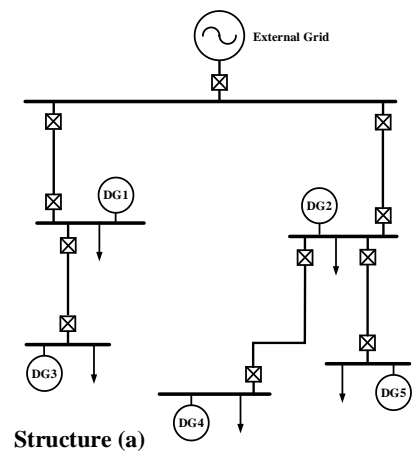

Structure (a)

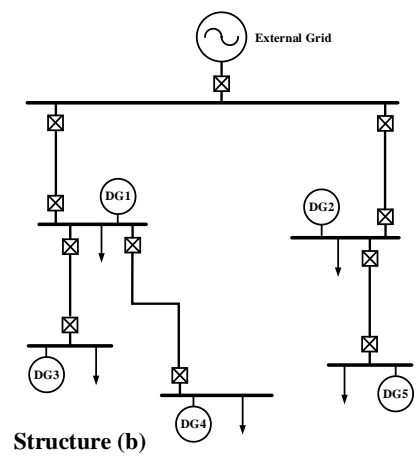

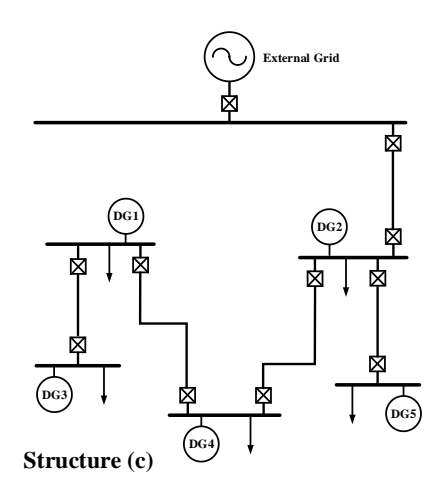

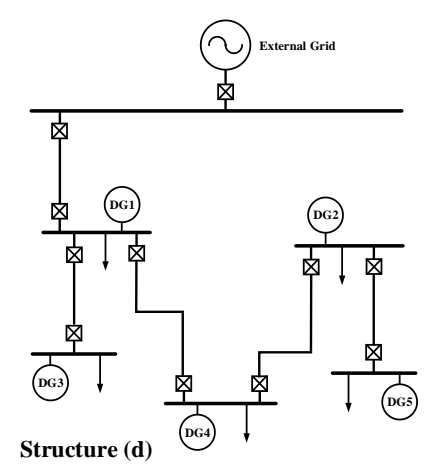

Figure 2. Different structures of studied microgrid 


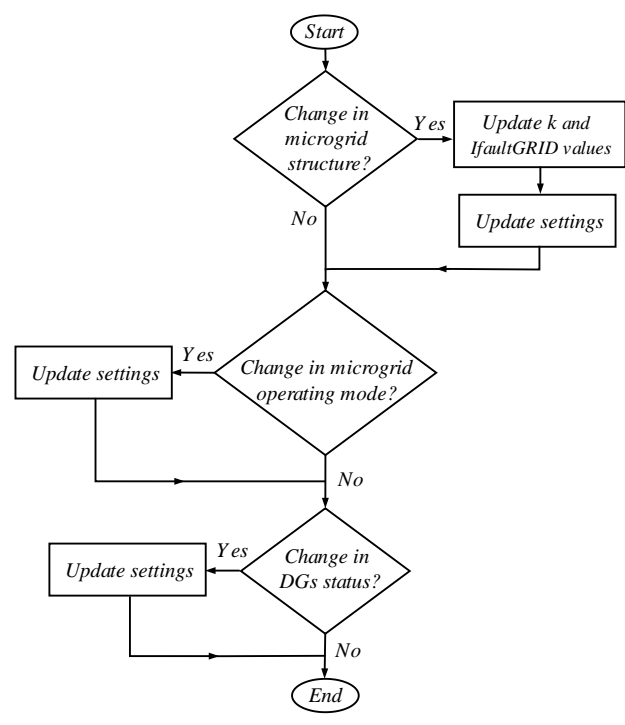

Figure 3. Suggested protection scheme flowchart

In this protection scheme, relays themselves monitor microgrid conditions using data obtained through telecommunication and adjust their settings according to the changes in microgrid conditions. Algorithm of suggested protection scheme is represented in Fig. 3. Microgrid condition variation which affect short-circuit current level could be categorized as follows: change in microgrid operating mode, change in DGs status and change in microgrid structure. Suggested protection scheme makes no limitations on relays type and using inverse time relays set or instantaneous time relays set is possible. However, relays used in this paper are instantaneous directional overcurrent relay.

\section{A. Calculation of relays operating current}

Ref. [18] uses a central unit for calculation instantaneous relays operating current via formula (1) and updating relays settings. In this protection scheme, if telecommunication of one component, especially central unit disconnects, total protection scheme will be collapsed. If functions of central unit left to relays, reliability of protection scheme will be increased. In this case with any problem for communication of one component such as a relay which is doing central units functions, protection task of specific relay will be collapsed and other relays will be doing their protection tasks as well. By defining backup protection scheme, this problem will be solved. In this case backup relay is monitoring microgrid conditions and with any change in these conditions, relay will update its settings to play backup role as well. In case of undetected short-circuit which could be caused by failed telecommunication of downstream relay, upstream relay will clear the fault. Operating current of relay can be calculated as follows:

$$
\begin{aligned}
\mathrm{I}_{\text {operating current }}= & \left(\mathrm{I}_{\text {faultGRID }}^{\mathrm{a}, \mathrm{b}, \mathrm{d}} \times \text { Operating Mode }\right)+ \\
& \sum_{\mathrm{i}=1}^{\mathrm{m}}\left(\mathrm{k}_{\mathrm{i}}^{\mathrm{a}, \mathrm{b}, \mathrm{c}, \mathrm{d}} \times \mathrm{I}_{\text {faultDGi}} \times \text { Status }_{\mathrm{DGi}}\right)
\end{aligned}
$$

Eq. (1) consists of two sets of data. First set are fixed data which stored in relays memory, including short-circuit current of external grid ( $\mathrm{I}_{\text {faultGRID }}$ ), maximum short-circuit current of DGs ( $\mathrm{I}_{\text {faultDG}}$ ) and impact factors (k). Second set are telecommunication data sent from microgrid components to corresponding relays, including position of intermediate $\mathrm{CB}^{4}$ between external grid and microgrid (Operating Mode) and DGs status (Status ${ }_{\text {DGi }}$ ). Position of $\mathrm{CBs}$ on two ends of a typical line will be sent to relays too. Relays use this information to monitor microgrid structure and with any change in microgrid structure, relays load suitable $\mathrm{I}_{\text {faultDG }}$ and $\mathrm{k}$ from their memory to use in (1). Therefore via second set of data, operating mode of microgrid, DGs status and microgrid structure will be determined. Calculation route to obtain data to be used in (1) will be explained later.

\section{1) Calculation of external grid short-circuit current}

In [19] the short-circuit current is calculated considering the Thevenin equivalent and using (2). In this equation, $V_{\text {th }}$ indicates the Thevenin voltage and has a constant value. However Thevenin impedance between the external grid and a desired point $\left(\mathrm{Z}_{\mathrm{th}}\right)$ is variable and depends on the distance [19]. So, impedance variation affects the IfaultGRID. As a result, occurring a change in equivalent impedance due restructured microgrid, $I_{\text {faultGRID values for each relay in each structure will }}$ be different.

$$
\mathrm{I}_{\text {faultGRID }}(\mathrm{d})=\frac{\mathrm{V}_{\mathrm{th}}}{\mathrm{Z}_{\mathrm{th}}(\mathrm{d})}
$$

\section{2) Calculation of DGs maximum short-circuit current}

According to microgrid voltage, DGs rated power and attachment circumstances to the microgrid (directly or via transformers), maximum short-circuit current of synchronous generators can be multiples of their rated current [20]. These coefficients are shown in Table I. IIDGs ${ }^{5}$ are not so capable as much as synchronous generators to provide short-circuit current due to semiconductor switches [19]. If DGs are equipped with FCL, between short-circuit current of DGs and maximum current of FCL, the lower one should be considered as the maximum short-circuit current of DG [21].

\section{3) calculation of impact factor}

According to Fig. 4 current injected by $\mathrm{DG}_{\mathrm{i}}$ during a shortcircuit, will have different values in different locations of microgrid, Due to impedance variation observed by $D_{i}$. This could be considered a multiple of the maximum short-circuit current of that DG $\left(\mathrm{I}_{\text {faultDGi }}\right)$ and display as $(\mathrm{k})$ which is a parameter between 0 and 1 [19]. The coefficient $\mathrm{k}$ shows effect of impedance variation observed by DG, therefore with restructuring of the microgrid and change short-circuit type and location, $\mathrm{k}$ values change. Calculation methods for $\mathrm{k}$ are provided in [19]. Ref. [22] presented two other methods for calculation $\mathrm{k}$ values. Impedance variation has no effect on IIDGs current and this current is changeable only by DGs controller. Consequently, the impact factor $\mathrm{k}$ is not applied to

\begin{tabular}{|c|c|c|c|c|c|}
\hline \multirow[b]{2}{*}{$\begin{array}{c}\text { Type of } \\
\text { Equipment }\end{array}$} & \multirow[b]{2}{*}{$\begin{array}{c}\text { Network } \\
\text { Voltage (kV) }\end{array}$} & \multicolumn{3}{|c|}{ Network Coupling } & \multirow[b]{2}{*}{ Comment } \\
\hline & & Direct & Transformer & $\begin{array}{c}\text { Power } \\
\text { Electronics }\end{array}$ & \\
\hline \multicolumn{6}{|l|}{$\begin{array}{l}\text { Synchronous } \\
\text { Generator }\end{array}$} \\
\hline - small & $0.4-33$ & $5-8$ & $3-7$ & - & $\begin{array}{l}\text { Power Rating } 0.5 \\
-5 \mathrm{MW} \\
\end{array}$ \\
\hline $\begin{array}{l}\text { - mediu } \\
\mathrm{m}\end{array}$ & $11-132$ & $5-6$ & $3-5$ & - & $\begin{array}{l}\text { Power Rating 5 - } \\
25 \mathrm{MW}\end{array}$ \\
\hline - large & 132 & - & $2.5-4.5$ & - & $\begin{array}{l}\text { Power Rating } \\
\text { Over } 25 \mathrm{MW} \\
\end{array}$ \\
\hline Fuel Cell & $0.4-33$ & $=$ & - & $1-1.2$ & \\
\hline
\end{tabular}
IIDGs and it is considered as 1 [19].

Table I. Ratio between short-circuit current and rated currents of DGs [20]

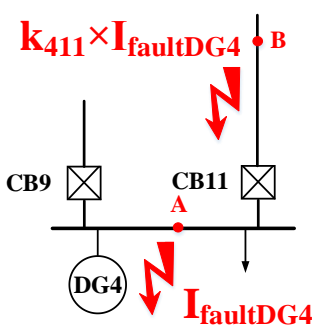

Figure 4. Short-circuit current of DG in various locations of microgrid [19] 


\section{4) Determination of microgrid opertating mode}

Position of intermediate $\mathrm{CB}$ between external grid and microgrid (CB1 in Fig. 1) determines operating mode of microgrid [21]. By changing in position of $\mathrm{CB} 1$, this circuit breaker will send its position to the all components of microgrid. In the IEC 61860 standard, a type of fast message introduced as GOOSE ${ }^{6}$ which became ready to be sent in a small time and covers all needs of suggested protection scheme. That is possible to not consider a definite destination for the GOOSE message and send this message periodically to all IEDs of microgrid every 4 milliseconds. By using this type of message to send position of $\mathrm{CB} 1$, it is mostly ensured that all components will get the message in minimum time and other relays recognize the microgrid is disconnected from external grid and has become islanded.

In order to equipment are able to send the GOOSE message, this property should be defined in configuration time. It is done by using the programming language $\mathrm{SCL}^{7}$ based on $\mathrm{XML}^{8}$ which explained in the IEC 61850 standard. The definition of the GOOSE messages for items that have been used in this article are presented in [17].

\section{5) Determination of DGs status}

With each DG turning on or off, a message will be sent to all components of the microgrid. This information will be sent easily by using the GOOSE message. Therefore relays will recognize changes in DGs status by receiving the GOOSE message and will update their protection settings according (1). The definition of this GOOSE message is proposed in [17].

\section{6) Determination of microgrid structure}

Information from CBs of both ends of lines could be used for determination of microgrid structure and lines status. It could be ensured that a specific line is in use/out of service, only when two CBs of both ends of the specific line are on/off. If information of one side of the line is sent, relays will remain on previous settings. This information could be sent using the GOOSE message too [17].

Fig. 5 shows the determination of microgrid structure. Using a specific line determined via AND logical function. Output of AND will be 1 when two inputs are 1 . This means that if receiving information of both ends of the specific line indicate that position of both CBs of the line are on, output of related AND will be 1 . On the other hand NOR logical function used for showing that the specific line is out of service. Output of NOR will be 1 when two inputs are 0 . According to Fig. 5 microgrid structure will be same with structure (a) in Fig. 2 when Line1, Line2, Line3, Line5 and Line6 are in use and Line4 is out of service.

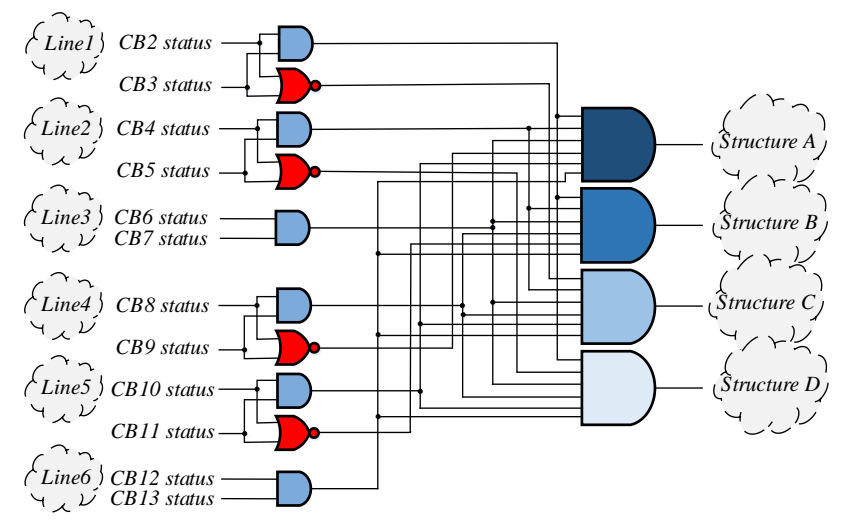

Figure 5. Logical circuit for detection of microgrid structure

\section{B. Backup protection scheme}

In discussion about backup protection, upstream relay will be indicated as relay $\mathrm{i}$ and relay $\mathrm{j}$ will be used for downstream relay. It is possible that main operating current of relay $j$ became higher than relay $i$, due to DGs connections in different point of microgrid. According to Fig. 6, relay R8 is backup for relay $\mathrm{R} 11$. In this condition main operating current of R11 which is accordant to injected current of DG1, DG3 and DG4, is possible to be higher than main operating current of R8 which is accordant to injected current of DG1 and DG3. Therefore existence of DGs will not allow to use main operating current of relay $\mathrm{j}$ as backup operating current of relay i. Another challenge for microgrid backup protection is changing backup protection role due to change in microgrid structure. Considering Fig. 1 and Fig. 2, in structure (b) R8 has no backup protection role while in structure (c) and (d) R8 is backup relay for R11.

Considering a short-circuit in protection zone of relay $\mathrm{j}$, short-circuit current observed by relay i consists of currents from the sources which are also injected during short-circuit in protection zone of relay i itself. In Fig. 6 while DG1, DG3 and DG4 are injecting current in protection zone of R11, shortcircuit current observed by R8 is originated from DG1 and DG3. For short-circuit in protection zone of R11, current observed by R8 will be lower than current for short-circuit in protection zone of R8. This happens due to the change in short-circuit location consequently, increase of distance and equal impedance observed by DG1 and DG3. Therefore in order to create backup protection in this scheme, it is possible to define two operating current as main operating current and backup operating current for each relay. If short-circuit current observed by relay i became higher than main operating current of relay $i$, short-circuit happened in protection zone of relay $i$ and relay i will send trip signal to its own CB immediately. If short-circuit current observed by relay $i$ was between the main operating current and backup operating current of relay $i$, short-circuit occurred in protection zone of relay $\mathrm{j}$. In this case, relay $i$ waits for a certain time delay for relay $j$ to do its protection role and clear short-circuit. After this time, if shortcircuit was not cleared, relay i proceeds to trip and do its backup role. The flowchart in Fig. 7 shows mechanism of short-circuit detection in this protection scheme.
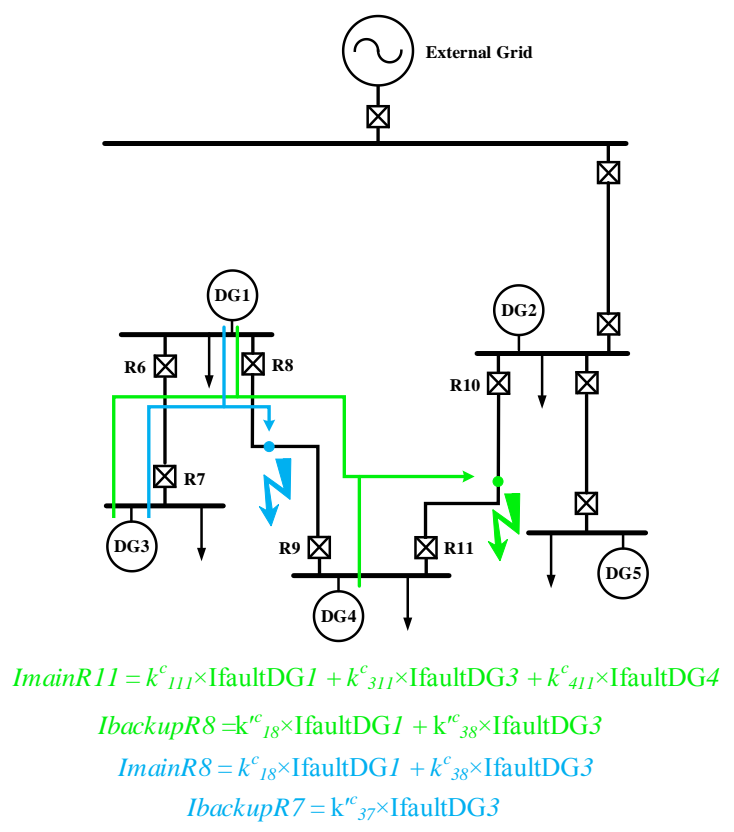

Figure 6. Short-circuit currents and relays settings during investigating backup protection 


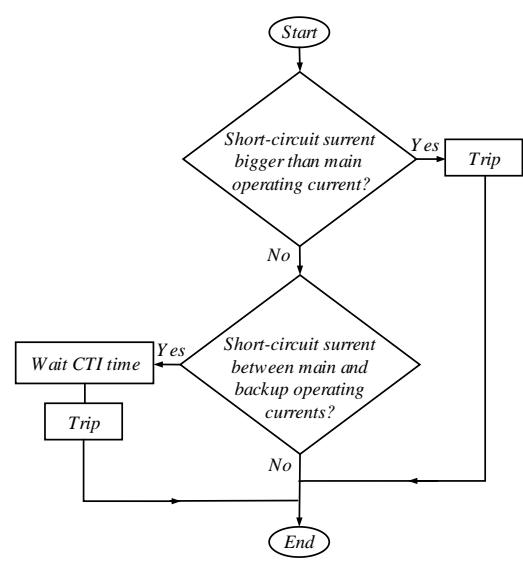

Figure 7. Flowchart of fault detection in backup protection scheme [19]

Backup protection also defined for relays at the highest level such as R11 in structure (a), relay R9 in structure (b) and R7 and R13 in all of the four structures of Fig. 2. If seen carefully, all those relays are in the downstream of specific DGs and only short-circuit current which observes these relays are upstream DGs currents. If an arrangement taken which disconnect upstream DGs after certain time, it could be claimed that these relays will be supported in case of unclear short-circuit. According to the IEEE 1547 [23], maximum operating time for DGs during short-circuit is 2 seconds and they should be disconnected from grid after 2 seconds.

\section{Relays coordination}

Two methods used to coordinate the instantaneous relays. In the first method, relay operating time considered constant and relay operating current is variable (diagram (a) in Fig. 8). The latter method is vice versa (diagram (b) in Fig. 8). Each of these have disadvantages, therefore a combination of the two methods is used in this article. The use of digital relays allows user to define a new characteristic for relays. In this new characteristic curve, two operating current as main and backup operating current is used and calculation procedure is discussed in this article.

In Fig. 9, if the main operating current of relay $\mathrm{f} 1$ is considered in accordance with the minimum amount of shortcircuit current (phase to ground short-circuit on bas B), it is possible that $\mathrm{f1}$ react in case of three-phase short-circuits in protection zone of $\mathrm{f} 2$ close to bas $\mathrm{B}$ and disconnects bas B. If the main current of relay $\mathrm{f} 1$ is considered according to the minimum three-phase short-circuit current (on the bas B) it is possible that f1 detect some short-circuit (two-phase to the ground, phase to the ground with impedance) occurred in its main protection zone with a delay. In case of distribution networks and microgrids it is possible to fix short-circuits with a delay about CTI, due to the lack of stability problems. So in order to avoid interference of relays functions, delay in operation of the main protection role is accepted and the main operating currents considered in accordance with the lowest three-phase short-circuit current in the main protection zone.

In order to cover all aspects of backup protection zone, the backup operating current considered according to phase to ground short-circuit at the end of the protected line (on the bas C). By changing the type of short-circuit, the equal impedance will be changed. So the impact of short-circuit type on (1) is obtainable using impedance related values such as $\mathrm{I}_{\text {faultGRID }}$ and $\mathrm{k}$. It is possible to model impedance of fault, considering a factor equals to 0.8 for backup operating current. If the threephase short-circuit occurs near bas $\mathrm{C}$, amount of this current will be higher than f1s backup operating current which is according to the phase to ground short-circuit on bas $\mathrm{C}$. In this case, malfunction of $\mathrm{f} 1$ as backup protection is possible. To solve this problem data used which the $\mathrm{f} 3$ sends to microgrid during short-circuit detection and clearing. Because of the delay in range of CTI between operating time of $\mathrm{f} 3$ and $\mathrm{f1}$, via using the GOOSE message and microgrid dimensions, it could be expected that the data sent from the relay $\mathrm{f} 3$ will be received by $\mathrm{f} 1$ and its function will be blocked.

\section{CALCULATING THE STORED VALUES IN THE MEMORY OF RELAYS}

In the last section, adaptive and decentralized protection scheme was proposed to protect the microgrid. According to the proposed algorithm in Fig. 3, each relay recognizes all the three incidental change in the microgrid conditions that causes changes in short-circuit current level and based on that specific change, relays change their setting themselves. By updating settings, relays in different conditions of microgrid operation will be able to detect the occurrence of short-circuit and clear it. Any change in the microgrid conditions affects relays backup protection role. The backup protection role of upstream relays is developed based on the algorithm shown in Fig. 3 and Fig. 7. Backup operating current is also calculated by using (1). This will cause an online change in backup protection settings based on the changes in the microgrid conditions. In this section the needed values in (1) for implementing the propose scheme will calculated. For this reason, the microgrid of Fig. 1 is used. See microgrid information on the Table II.

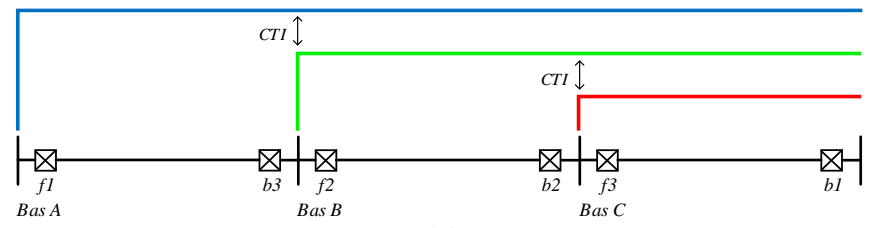

(a)

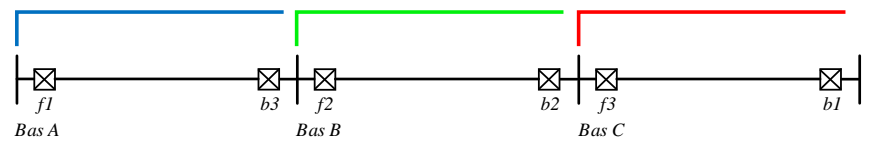

(b)

Figure 8. Conventional instantaneous relays coordination methods

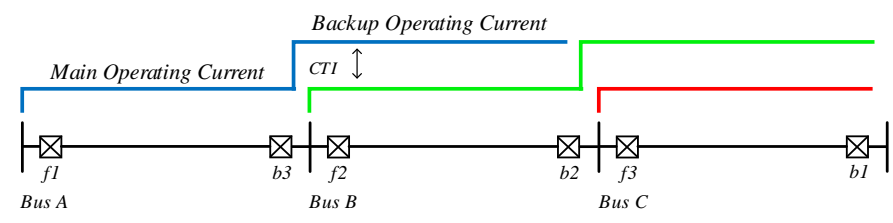

Figure 9. Proposed instantaneous relays coordination method

Table II. Microgrid information

\begin{tabular}{|c|c|c|c|c|}
\hline DGs & DG Type & $\begin{array}{l}\text { Rated Power } \\
\text { (MVA) }\end{array}$ & Lines & $\begin{array}{c}\begin{array}{c}\text { Length } \\
(\mathrm{km})\end{array} \\
\end{array}$ \\
\hline DG1 & Fuel Cell & 1 & Linel & 2 \\
\hline DG2 & Fuel Cell & 1 & Line2 & 2 \\
\hline DG3 & Synchronous Generator & 2 & Line3 & 1 \\
\hline DG4 & Synchronous Genera & 4 & Line4 & 1 \\
\hline DG5 & Synchronous Generator & 2 & Line5 & 1 \\
\hline \multirow{2}{*}{ Loads } & \multirow{2}{*}{ Active Power (MW) } & \multirow{2}{*}{$\begin{array}{c}\text { Reactive Power } \\
\text { (MVAr) }\end{array}$} & Line6 & 1 \\
\hline & & & \multirow{3}{*}{\multicolumn{2}{|c|}{$\begin{array}{c}\text { External Grid } \\
\text { Short-Circuit } \\
\text { Power }=35 \text { MVA }\end{array}$}} \\
\hline 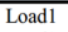 & 4 & 3 & & \\
\hline Load2 & 4 & 2 & & \\
\hline Load3 & 3 & 1 & \multirow{3}{*}{\multicolumn{2}{|c|}{$\begin{array}{c}\text { Microgrid } \\
\text { Voltage }=20 \mathrm{kV}\end{array}$}} \\
\hline Load4 & 2 & 1 & & \\
\hline Load5 & 3 & 2 & & \\
\hline
\end{tabular}




\section{A. Calculating needed values to implement main protection}

On the basis of (1), some values that should already be calculated offline and stored in the memory of instantaneous overcurrent relays are: short-circuit current of external grid, maximum short-circuit current of DGs and impact factors.

\section{1) External grid short-circuit current in main protection} zone

Short-circuit current injected from the external grid using (2) is determined. Fig. 10 shows how to change the amount of this current based on the change of three-phase short-circuit location. According to the Fig. 10, it is clear that short-circuit current of external grid is dependent on impedance. It can be concluded that the restructuring of the microgrid, the external grid impedance changes and certainly its injected short-circuit current will be changed.

Because of the use of directional relays, some of these relays do not feel current injection from some sources and presence or absence of these sources does not influence on relays settings. Note that this feature is dependent on the microgrid structure and one relay may see short-circuit current of external grid in a microgrid structure and does not see in another structure. For example, injected short-circuit current from the external grid can be seen by relay R8 in the structure (b) but it cannot be seen in the structure (c) of Fig. 2.

Based on section 2-3 for coordinating relays, minimum amount of three-phase short-circuit current is used, which is achieved by happening of a short-circuit at the end of the main protection zone. Table III shows the three-phase short-circuit current of external grid seen by relays for short-circuit happened at the end of main protection zones.

\section{2) DG's maximum short-circuit current}

Using rated power and voltage of DGs that are listed in Table II, rated current of them can be determined. With the DGs rated currents and by considering section 2-1-2, maximum short-circuit current of each DG can be determined (Table IV). In this microgrid, DGs without transformer are connected to the network. According to the Table I and DGs powers in the Table II, the maximum short-circuit current for synchronous DGs is 6 times bigger than rated current and for IIDGs the same as rated current is considered.

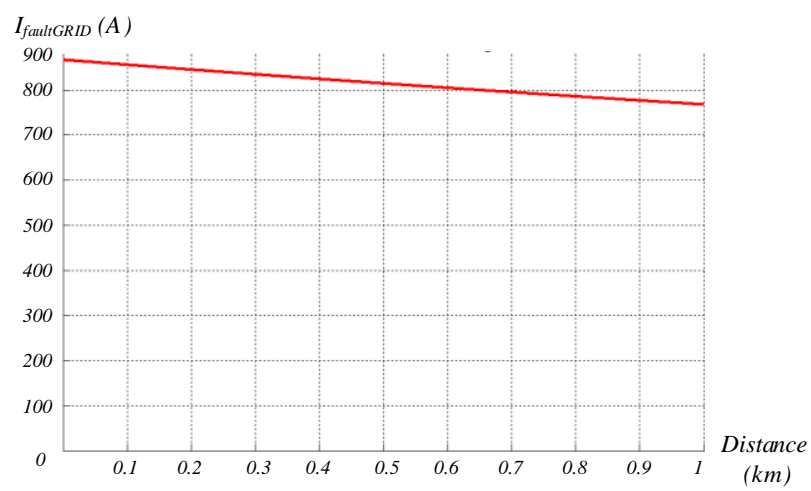

Figure 10. Injected current from external grid based on change of short-circuit location

Table III. Minimum three-phase short-circuit current of external grid seen by relays

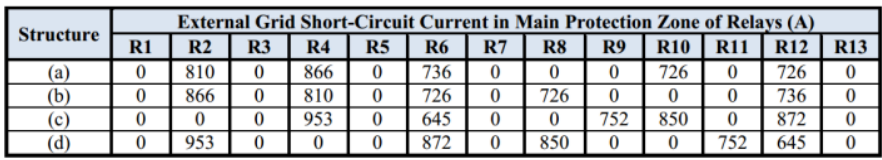

Table IV. Maximum short-circuit current of DGs

\begin{tabular}{|c|c|c|c|}
\hline DGs & $\begin{array}{c}\text { Rated Current } \\
(\mathbf{A})\end{array}$ & Coefficient & $\begin{array}{c}\text { Maximum Short-Circuit } \\
\text { Current of DGs (A) }\end{array}$ \\
\hline DG1 & 30 & 1 & 30 \\
\hline DG2 & 30 & 1 & 30 \\
\hline DG3 & 60 & 6 & 360 \\
\hline DG4 & 120 & 6 & 720 \\
\hline DG5 & 60 & 6 & 360 \\
\hline
\end{tabular}

\section{3) Values of Matrix $K$}

According to [19], these values are not calculated for IIDG and they are only calculated for synchronous generators (DG3, DG4 and DG5). This value is considered 1 for all IIDGs. The values of $\mathrm{k}$ model microgrid structure and impedance of lines in calculating operating current of relays. The Fig. 11 shows the amount of specific $\mathrm{k}$ in four different structure of microgrid. Obviously, by changing short-circuit location from the beginning of line to the end of it, the value of $\mathrm{k}$ reduces. This occurs due to an increase in the impedance seen by DG.

Because of directional relays usage, some of relays are not felt injected short-circuit current by some DGs. For example, by a short-circuit occurrence on Line4 in the structure (d) of Fig. 2, R8 will not sense the injection current from the DG5. This event model with $\mathrm{k}_{58}^{\mathrm{d}}$ amount equal 0 . In the following $\mathrm{K}$ matrixes for 4 different structure of microgrid are mentioned. Matrix (3) corresponds to structure (a), (4) related to the structure (b), (5) related to structure (c), and (6) is related to the structure (d). These values are calculated for three-phase short-circuit at the end of the main protection zone.

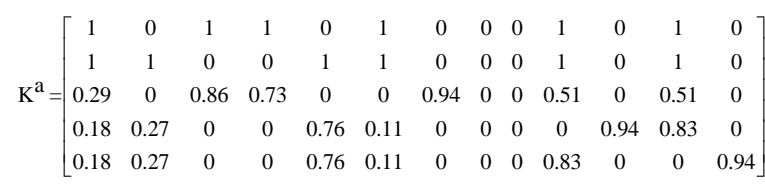

$\mathrm{K}^{\mathrm{b}}=\left[\begin{array}{ccccccccccccc}1 & 0 & 1 & 1 & 0 & 1 & 0 & 1 & 0 & 0 & 0 & 1 & 0 \\ 1 & 1 & 0 & 0 & 1 & 1 & 0 & 1 & 0 & 0 & 0 & 1 & 0 \\ 0.18 & 0 & 0.76 & 0.27 & 0 & 0 & 0.94 & 0.83 & 0 & 0 & 0 & 0.11 & 0 \\ 0.18 & 0 & 0.76 & 0.27 & 0 & 0.83 & 0 & 0 & 0.94 & 0 & 0 & 0.11 & 0 \\ 0.29 & 0.73 & 0 & 0 & 0.86 & 0.51 & 0 & 0.51 & 0 & 0 & 0 & 0 & 0.94\end{array}\right]$ $\mathrm{K}^{\mathrm{C}}=\left[\begin{array}{ccccccccccccc}1 & 0 & 0 & 0 & 1 & 1 & 0 & 1 & 0 & 0 & 0 & 1 & 0 \\ 1 & 0 & 0 & 0 & 1 & 1 & 0 & 0 & 1 & 1 & 1 & 1 & 0 \\ 0.39 & 0 & 0 & 0 & 0.5 & 0 & 0.94 & 0.9 & 0 & 0 & 0 & 0.5 & 0 \\ 0.54 & 0 & 0 & 0 & 0.61 & 0.71 & 0 & 0 & 0.9 & 0 & 0.94 & 0.6 & 0 \\ 0.54 & 0 & 0 & 0 & 0.81 & 0.65 & 0 & 0 & 0.76 & 0.86 & 0 & 0 & 0.94\end{array}\right]$ $\mathrm{K}^{\mathrm{d}}=\left[\begin{array}{ccccccccccccc}1 & 0 & 1 & 0 & 0 & 1 & 0 & 1 & 0 & 0 & 0 & 1 & 0 \\ 1 & 0 & 1 & 0 & 0 & 1 & 0 & 0 & 1 & 1 & 1 & 1 & 0 \\ 0.56 & 0 & 0.81 & 0 & 0 & 0 & 0.94 & 0.86 & 0 & 0 & 0.76 & 0.65 & 0 \\ 0.54 & 0 & 0.6 & 0 & 0 & 0.6 & 0 & 0 & 0.86 & 0 & 0.9 & 0.71 & 0 \\ 0.39 & 0 & 0.5 & 0 & 0 & 0.5 & 0 & 0 & 0.8 & 0.9 & 0 & 0 & 0.94\end{array}\right]$

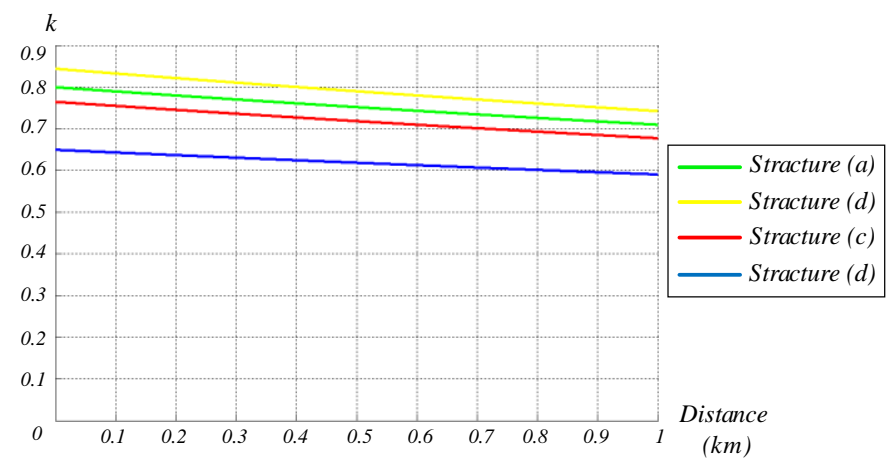

Figure 11. Value of specific $\mathrm{k}$ in different structures of the microgrid based on change of short-circuit location 
B. Obtaining the needed values to implement backup protection

With changing microgrid structure, backup protection roles of relays are also changes. Table $\mathrm{V}$ shows relays backup functions in different structures of the microgrid. The calculation of backup operating current also needs to get shortcircuit current of external grid, maximum short-circuit current of DGs and impact factors, related to the backup protection.

\section{1) Short-circuit current of external grid in protection zone} of downstream relay

This current is measurable using (2). According to section $2-3$, this current is injected from the external grid when there is a phase to ground short-circuit in the downstream relays protection zone. It is possible that by happening a short-circuit in the protection zone of relay $\mathrm{j}$, short-circuit current is injected from external grid but relay $i$ does not sense this current. Therefore, short-circuit current of external grid in the protection zone of relay $\mathrm{j}$, should be a current that relay $\mathrm{i}$ could see that, too. For example, by happening a short-circuit on Line5 in structure (a) of Fig. 2, the current is injected from external grid, but R8 which is backup relay or R11 does not feel this current and just by using the short-circuit current from DG1 and DG3 and after a delay time, performs its backup protection role. As seen in Table VI, for some relays two amounts are calculated. This is because the specific relay has a duty to backup two relays. In this case the lowest amount is used. According to the subjects mentioned in the previous section, this current is dependent on the impedance and therefore, it is affected by short-circuit location, microgrid structure, and type of short-current.

\section{2) Maximum short-circuit current of DGs}

These values are the same values discussed in the section 3-1-2 and they will not have any change.

\section{3) Values of matrix $K$}

Value $\mathrm{k}_{\mathrm{mi}}$ indicate contribution of the $\mathrm{DG}_{\mathrm{m}}$ in the shortcircuit current seen from the relay $i$ located in the relay $j$ protection zone. For example $\mathrm{k}^{\prime \mathrm{d}}{ }_{18}$ represents DG1 participation in the event of a short-circuit in the area where R8 has duty to backup it. It is 8's duty to backup R11, so $\mathrm{k}^{\prime \mathrm{d}}{ }_{18}$ by regarding the occurrence of a short-circuit in R11's protection zone in structure (d) is obtained. Matrix (7) corresponds to structure (a), (8) is related to the structure (b), (9) is related to structure (c), and (10) is related to the structure (d). The values is calculated for phase to ground short-circuit at the end of backup protection zone. Due to support of one relay from two other relays, in some cases two amounts are calculated for $\mathrm{k}$, but the smaller amount is used.

Table V. Backup protection roles of relays

\begin{tabular}{|c|c|c|c|c|c|c|c|c|c|c|c|c|c|}
\hline Structure & R1 & R2 & R3 & R4 & R5 & R6 & R7 & R8 & R9 & R10 & R11 & R12 & R13 \\
\hline (a) & - & R6 & R4 & R10 & R2 & - & R3 & - & - & - & R5 & - & R5 \\
\hline (b) & - & R6 & R4 & R12 & R2 & - & R3 & - & - & - & - & - & R5 \\
\hline (c) & - & - & - & R10 & - & - & R8 & R11 & R6 & R9 & R5 & - & R5 \\
\hline (d) & - & R6 & - & - & - & - & R3 & R11 & R3 & R9 & R12 & - & R10 \\
\hline
\end{tabular}

Table VI. Short-circuit current of external grid in protection zone of downstream relay

\begin{tabular}{|c|c|c|c|c|c|c|c|c|c|c|c|c|c|}
\hline \multirow{2}{*}{ Structure } & \multicolumn{10}{|c|}{ External Grid Short-Circuit Current in Backup Protection Zone of Relays (A) } \\
\cline { 2 - 19 } & R1 & R2 & R3 & R4 & R5 & R6 & R7 & R8 & R9 & R10 & R11 & R12 & R13 \\
\hline (a) & 0 & 440 & 0 & 436 & 0 & 0 & 0 & 0 & 0 & 0 & 0 & 0 & 0 \\
\hline (b) & 0 & 436 & 0 & 436 & 0 & 0 & 0 & 0 & 0 & 0 & 0 & 0 & 0 \\
\hline (c) & 0 & 0 & 0 & 510 & 0 & 0 & 0 & 0 & 387 & 451 & 0 & 0 & 0 \\
\hline (d) & 0 & 523 & 0 & 0 & 0 & 0 & 0 & 451 & 0 & 0 & 387 & 0 & 0 \\
\hline
\end{tabular}

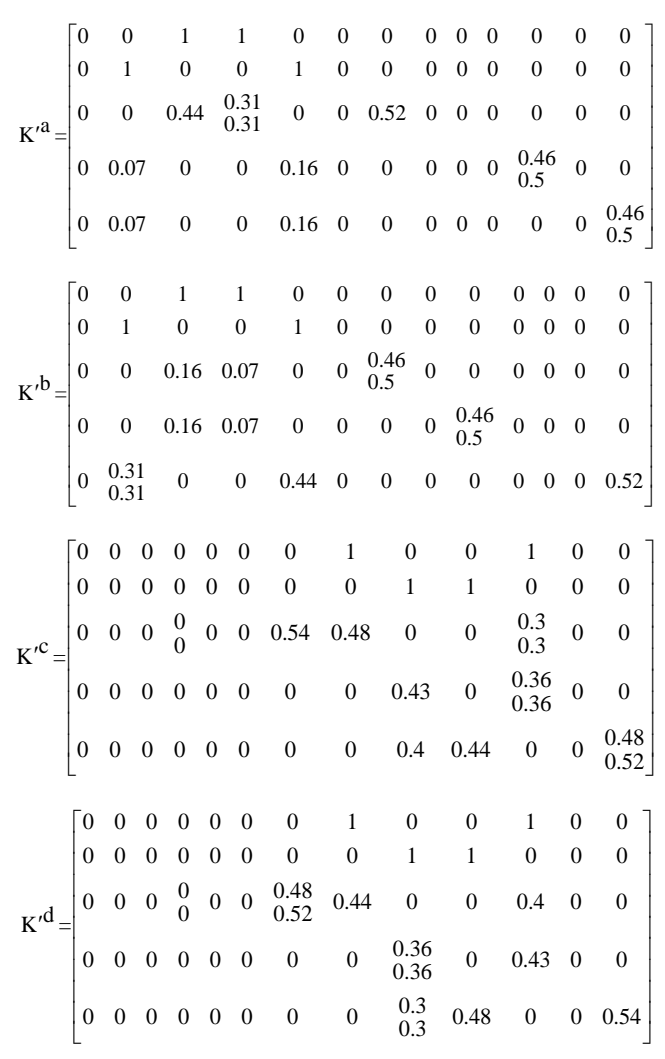

\section{Simulation AND Results}

In this section in order to validate this scheme, the algorithm of Fig. 3 for the main and backup protection using values obtained in the previous section will be implemented. So, for each relay an equation like (1) is intended. Relays, receive information about changes in microgrid conditions by monitoring microgrid and change their main protection and backup operating current for new condition by using predetermined values. Using the results obtained in this section, the ability of this protection scheme in microgrid conditions monitoring, change of relays settings and microgrid protection will be investigated.

To show different aspects of the protection scheme, special scenario will be applied; it includes:

Step1: All DGs except DG1 are on and microgrid is connected to the external grid.

Step2: DG4 is turning off.

Step3: microgrid continues working independent of the external grid

\section{Step4: DG1 and DG4 are turning on.}

Step5: microgrid is connected to the external grid again.

Some parts of the simulation results are given below. Table VII contains the main and backup operating current for the relays R3 and R4. According to the values specified in Table VII some relays are not sensitive to DGs enters and exists, or even to change of microgrid operation mode. For example, for R3 from structure (b) with DG4s turning off, main operating current drops from $820 \mathrm{~A}$ to $270 \mathrm{~A}$ and backup operating current from $170 \mathrm{~A}$ to $60 \mathrm{~A}$. These values do not change when microgrid becomes islanded and remain at $270 \mathrm{~A}$ and $60 \mathrm{~A}$. Therefore, settings of R3 in structure (b) are independent of external grids effects. In step4, both main and backup operating current change. New values that respectively equal $850 \mathrm{~A}$ and $200 \mathrm{~A}$ are different from the initial values and by considering that the external grid does not effect of 
R3s settings, it can be claimed that this relay is sensitive to both DG1 and DG4 and the these DGs effect on settings of this relay. Some relays including R3 in structure (d) does not have backup role and some relays in some structures are not in use. For example, R4 relay in the structure (d) are not in use due to the lack of Line 2 existence.

The only source that R4 in structure (c) of Fig. 2 senses its current is the external grid. It is obvious that with islanding microgrid from external grid, R4 settings based on (1) must equal 0 , but it should be noted that at any moment microgrid can be connected to the external grid. If this connection is established and the main or backup operating current of R4 is regulated to be 0 , relay will detect load current as a shortcircuit current and microgrid will be islanded again. Therefore it is proposed that in this step, R4 has amounts equal to the amounts of the step that microgrid and external grid are connected together. This is true about R9 in structure (b). In structure (b), R9 just feels short-circuit current of DG4 and when this DG is turning off, the R9s settings based on equation should be 0 . In the case that the main and backup operating current for R9 are chosen to be 0 and DG4 is connected to the microgrid, R9 will detect its injection current as a short-circuit current and it will separate DG4 from microgrid again. So, it is recommended that in this structure, settings of R9s settings remain stable and not change with DG4 turning on or off.

To investigate the diagnostic efficacy of a short-circuit happening by this protection scheme, short-circuit current level was compared to the operating currents of R10 in structure (c). Due to having minimum short-circuit current, location of short-circuit to analyze the main protection is considered the end of Line5 and for analyzing backup protection, the end of Line4. In graph (a) of Fig. 12, threephase short-circuit current level at the end of R10's main protection zone is compared to R10 main operating current. It is claimed that the main operating current is always less than the minimum three-phase short-circuit current in the main

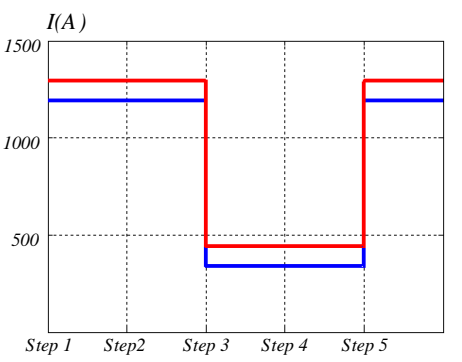

(a)

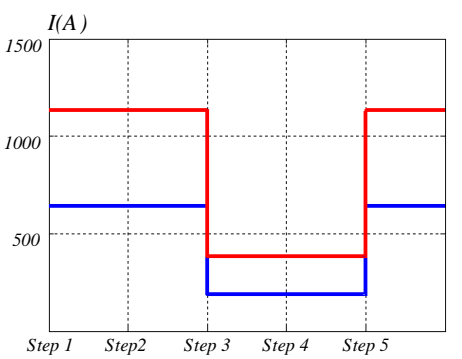

(d)

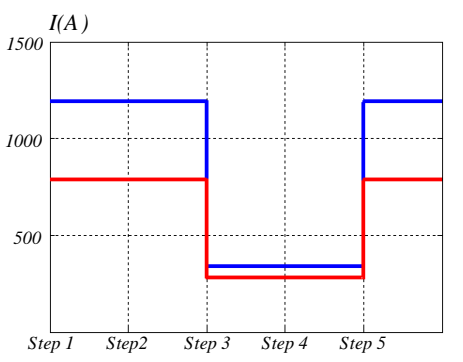

(b)

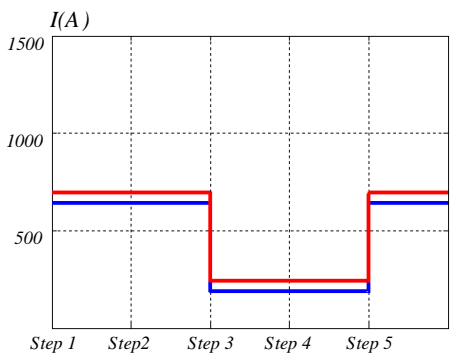

(e) protection zone and the relay is able to detect it. As mentioned in section 2-3 to have coordination between the relays, R10 may not recognize some short-circuit in the main protection area by using the main short-circuit current. Graph (b) of Fig. 12 shows that R10 is not able to detect phase to ground shortcircuit at the end of its main protection zone. Graph (c) of Fig. 12 suggests that the short-circuit in downstream relay zone is detected by backup operating current and after CTI time passed, the relay clears the short-circuit. Graph (d) of Fig. 12, minimum three-phase short-circuit current and Graph (e) of Fig. 12 shows the minimum phase to ground short-circuit seen from relay $\mathrm{R} 10$ at the end of R10 backup protection zone. As seen, relay has the ability to detect both short-circuits using the backup operating current. Graph (f) of Fig. 12 also compares short-circuit in backup protection zone which is seen from R10 with the main operating current of R10. It is proved that under any circumstances the relay does not recognize the short-circuit in the backup protection zone as a fault. In other words, the main protection and backup protection duties do not interfere with each other.

Table VII. Main and backup operating current of R3 and R4

\begin{tabular}{|c|c|c|c|c|c|}
\hline \multirow[b]{2}{*}{ Structures } & \multirow[b]{2}{*}{ Steps } & \multicolumn{2}{|c|}{ R3 } & \multicolumn{2}{|c|}{ R4 } \\
\hline & & $\begin{array}{c}\text { Main } \\
\text { Operating } \\
\text { Current }\end{array}$ & $\begin{array}{c}\text { Backup } \\
\text { Operating } \\
\text { Current }\end{array}$ & $\begin{array}{c}\text { Main } \\
\text { Operating } \\
\text { Current }\end{array}$ & $\begin{array}{c}\text { Backup } \\
\text { Operating } \\
\text { Current }\end{array}$ \\
\hline \multirow{5}{*}{ (a) } & Step 1 & 310 & 160 & 1130 & 550 \\
\hline & Step 2 & 310 & 160 & 1130 & 550 \\
\hline & Step 3 & 310 & 160 & 260 & 110 \\
\hline & Step 4 & 340 & 190 & 290 & 140 \\
\hline & Step 5 & 340 & 190 & 1160 & 580 \\
\hline \multirow{5}{*}{ (b) } & Step 1 & 820 & 170 & 1100 & 510 \\
\hline & Step 2 & 270 & 60 & 910 & 460 \\
\hline & Step 3 & 270 & 60 & 100 & 30 \\
\hline & Step 4 & 850 & 200 & 320 & 110 \\
\hline & Step 5 & 850 & 200 & 1130 & 550 \\
\hline \multirow{5}{*}{ (c) } & Step 1 & - & - & 953 & 510 \\
\hline & Step 2 & - & - & 953 & 510 \\
\hline & Step 3 & - & - & $0(953)$ & $0(510)$ \\
\hline & Step 4 & - & - & $0(953)$ & $0(510)$ \\
\hline & Step 5 & - & - & 953 & 510 \\
\hline \multirow{5}{*}{ (d) } & Step 1 & 930 & - & - & - \\
\hline & Step 2 & 500 & - & - & - \\
\hline & Step 3 & 500 & - & - & - \\
\hline & Step 4 & 960 & - & - & - \\
\hline & Step 5 & 960 & - & - & - \\
\hline
\end{tabular}

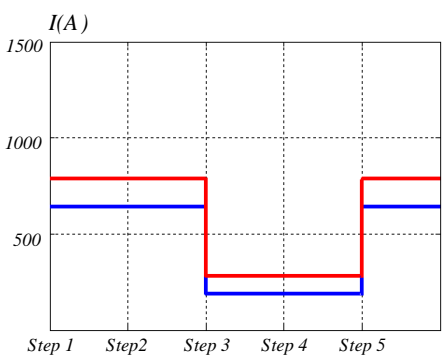

(c)

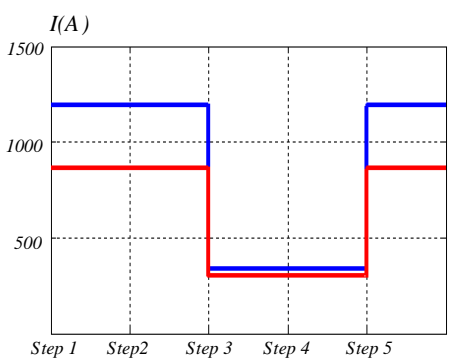

(f)

Figure 12. Comparison of different short-circuit currents level in structure (c) of microgrid with R10 operating currents. a) minimum three-phase short-circuit current level at main protection zone with main operating current, b) minimum phase to ground short-circuit at main protection zone with main operating current, c) minimum phase to ground short-circuit at main protection zone with backup operating current, d) minimum three-phase short-circuit current level at backup protection zone with backup operating current, e) minimum phase to ground short-circuit current level at backup protection zone with backup operating current, f) maximum three-phase short-circuit current level at backup protection zone with main operating current 


\section{CONCLUSION}

In this paper, a decentralized and adaptive protection scheme for microgrid was presented. Relay by monitoring microgrid recognizes changes in microgrid structure, microgrid operating mode and DGs status then update its protection settings based on these changes. This protection scheme was implanted on a microgrid with instantaneous relays. The problem with instantaneous relays that makes them less popular than inverse relays is lack of these relays as backup protection for downstream relays and their coordination issue. In this paper, assuming that used relays are digital relays, a new characteristic curve is provided for instantaneous relays then coordination method according to the new characteristic curve are presented.

\section{REFERENCES}

[1] M. Ghotbi Maleki, "Decentralized microgrid protection according to the IEC 61850" MSc. dissertation, Dept. electrical \& computer Eng., Univ. Shahid Beheshti, 2015.

[2] T.S. Ustun, C. Ozansoy, A. Zayegh, "Recent Developments in Microgrids and Example Cases Around the World-A Review," Renewable and Sustainable Energy Review, vol. 15, pp. 4030-4041, Oct. 2011.

[3] N. scheafer, T. Degner, A. Shustov, T. Keli, J. Jaeger, "Adaptive Protection System for Distribution Networks with Distributed Energy Resources," in Proc. 2012 Development in Power System Protection (DPSP) Conf.

[4] T.S. Ustun, C. Ozansoy, A. Zayegh, "Modeling of a Centralised Microgrid Protection System and Distributed Energy Resources According to IEC 61850-7-420," IEEE Trans. on Power System, vol. 27, pp. 1560-1567, Aug. 2012.

[5] T.S. Ustun, C. Ozansoy, A. Zayegh, "Simulation of Communication Infrastructure of a Centralized Microgrid Protection System Based on IEC 61850-7-420," in Proc. 2012 IEEE Smart Grid Communications Conf., pp. 492-497.

[6] T.S. Ustun, C. Ozansoy, A. Zayegh, "Modeling and Simulation of a Microgrid Protection System with Central Protection Unit," in Proc. 2013 IEEE TENCON Spring Conf., pp. 5-9.

[7] B.P. Bhattarai, B. Bak-Jensen, S. Chaudhary, J.R. Pillai, “An Adaptive Overcurrent Protection in Smart Distribution Grid," in Proc. 2015 IEEE PowerTech Conf., pp. 1-6.

[8] J. Ma, X. Wang, Y. Zhang, Q. Yang, A.G. Phadke “A Novel Adaptive Current Protection Scheme for Distriburion Systems with Distributed Generation," Electrical Power and Energy Systems, vol. 43, pp. 14601466, Dec. 2012.

[9] H.H. Zeineldin, E.F. El-Saadany, M.M.A. Salma, "Protective Relay Coordination for Micro-grid Operating Using Particle Swarm Optimization," in Proc. 2006 Large Engineering Systems Conf.

[10] M. Singh, "Protection Coordination in Grid Connected \& Islanded Modes of Micro-grid Operations," in Proc. 2013 IEEE Inovative Smart Grid Technologies-Asia Conf., pp. 1-6.
[11] S.M. Brahma, A. Girgis, "Development of Adaptive Protection Scheme for Distribution Systems With High Penetration of Distributed Generation," IEEE Trans. on Power Delivery, vol. 19, pp. 56-63, 2004.

[12] B. Li, Y. Li, Z. Bo, A. Klimek, "Design of Protection and Control Scheme for Microgrid Systems," in Proc. 2009 IEEE International Universities Power Engineering Conf.(UPEC).

[13] M. Khederzadeh, "Adaptive Setting of Protective Relays in Microgrid in Grid-Connected and Autonomous Operation," in Proc. 2012 Developments in Power System Protections Conf.

[14] R.R. Ferreira, A.P. Grilo, J.C. Teixeira, R.C. Sants, "Method for Adaptive Overcurrent Protection of Distribution Systems With Distributed Synchronous Generation," in Proc. 2015 IEEE Power and Energy Society Meeting, pp. 1-5.

[15] P. Mahat, Z. Chen, B. Bak-Jensen, C.L. Bak "A Simple Adapive Overcurrent Protection of Distributed Systems With Distributed Generation," IEEE Trans. on Smart Grid, vol. 2, pp. 428-437, 2011.

[16] Communication Networks and Systems for Power Utility Automation, IEC 61850, 2013.

[17] M. Ghotbi Maleki, H. Javadi, M. Khederzadeh, M. Bayrami, S. Farajzadeh, "Data Exchange Standardization in a Microgrid Protection Scheme According to the IEC 61850," in Proc. 2015 Smart Grid Conf. (SGC2015), Iran.

[18] T.S. Ustun, C. Ozansoy, A. Zayegh, "A Microgrid Protection System with Central Protection Unit and Extensive Communication," in Proc. 2011 Environment and Electrical Engineering Conf.

[19] T.S. Ustun, C. Ozansoy, A. Zayegh, "Fault Current Coefficient and Time Delay Assignment for Microgrid Protection System With Central Protection Unit," IEEE Trans. on Power System, vol. 28, pp. 598-606, May 2013.

[20] C. Mortley, "Contribution to Distribution Network Fault Level from the Connection of Distributed Generation," KEMA, UK, Tech. Rep. (DG/CG/00027/00/00), 2005.

[21] T.S. Ustun, C. Ozansoy, A. Zayegh, "A Central Microgrid Protection System for Networks With Fault Current Limiters," in Proc. 2011 Environment and Electrical Engineering Conf.

[22] M. Abdel-salam, A. Ahmed, H. Ziedan, R.M. Kamel, K. Sayed, M. Amery, M. Khalaf, "An Adaptive Protection System for Micro-Grid Operating in Grid Connected and Islanded Modes," in Proc. 2013 INTELEC Conf., pp. 1-6, Germany.

[23] IEEE Standard for Interconnecting Distributed Resources With Electric Power Systems, IEEE Std 1547, 2003.

\footnotetext{
${ }^{1}$ Distributed Generator

${ }^{2}$ Particle Swarm Optimization

${ }^{3}$ Linear Programming

${ }^{4}$ Circuit Breaker

${ }^{5}$ Inverter Interface Distributed Generation

${ }^{6}$ Generic Object Oriented Substation Events

${ }^{7}$ Substation Configuration Language

${ }^{8}$ eXtensible Markup Language
} 